\title{
Section $V$
}

Waterways, ports and hydraulic engineering constructions 
УДК 627.152.121:553.62

DOI: https://doi.org/10.37890/jwt.vi65.138

\title{
ПРОГНОЗ РУСЛОВЫХ ДЕФОРМАЦИЙ И ОСОБЕННОСТИ РАЗРАБОТКИ ПОЙМЕННЫХ КАРЬЕРОВ НЕРУДНЫХ СТРОИТЕЛЬНЫХ МАТЕРИАЛОВ В МЕАНДРИРУЮЩИХ РУСЛАХ РЕК С УЧЕТОМ БЕЗОПАСНЫХ УСЛОВИЙ СУДОХОДСТВА (НА ПРИМЕРЕ Р.БЕЛАЯ)
}

\author{
А.Н. Ситнов \\ Волжский государственный университет водного транспорта, \\ г. Нижний Новгород, Россия \\ М.В. Шестова \\ Волжский государственный университет водного транспорта, \\ 2. Нижний Новгород, Россия \\ Ю.Е. Воронина \\ Волжский государственный университет водного транспорта, \\ г. Нижний Новгород, Россия
}

\begin{abstract}
Аннотация. Пойменные карьеры нерудных строительных материалов (НСМ) оказывают минимальное влияние на водный режим и судоходные условия водоема в районе своего расположения. Однако освоение таких месторождений имеет свои особенности, особенно, если они находятся в меандрирующих руслах крупных судоходных рек. На примере пойменного карьера, расположенного на устьевом участке р.Белой (1757$1763 \mathrm{\kappa м),} \mathrm{были} \mathrm{рассмотрены} \mathrm{условия} \mathrm{разработки} \mathrm{таких} \mathrm{объектов} \mathrm{с} \mathrm{учетом} \mathrm{обеспече-}$ ния безопасности судоходства; дана оиенка состояния русла и выполнен прогноз русловых деформаиий на основе анализа динамики изменения основных параметров излучин. Был сделан вывод о возможности добычи песчано-гравийных пород на исследуемом участке реки Белая только при условии комплексного решения вопросов, связанных с безопасностью судоходства. В первую очередь, это спрямление меандра и перенос судового хода в новую капитальную прорезь.
\end{abstract}

Ключевые слова: пойменные карьеры НСМ, прогноз русловых деформачий, меандрирующие русла рек, судоходные условия

\section{Введение}

Речная экосистема в стадии своего динамического равновесия характеризуется сложившимися гидрологическими, геохимическими и биологическими циклами и ее функционирование осуществляется по принципу обратной связи. Поэтому реакция системы на любое вторжение в природную среду зависит от степени и продолжительности техногенного воздействия и в каждом конкретном случае требует проведения комплексных исследований. Гидрологический и русловой режимы представляют собой одни из наиболее сложных процессов взаимодействия руслового потока со слагающим аллювием ложа реки.

Пойменные карьеры нерудных строительных материалов (НСМ) более желательны в реализации, поскольку оказывают минимальное влияние на водный режим и судоходные условия в районе своего расположения. Однако освоение таких месторождений имеет свои особенности, требующие предварительной проработки ряда вопросов. При комплексном же решении разработка такого типа карьера может вестись не только с целью добычи НСМ, но и способствовать улучшению судоходных условий на конкретном участке водоема. 


\section{Постановка задачи}

Объектом исследования является возможный участок разработки песчаногравийных пород (ПГП) на приустьевом участке р.Белая в интервале 1757-1763 км судового хода (по Атласу ЕГС ЕЧ РФ том 10) (рис.1). Предполагаемое месторождение ПГП находится в правобережной пойме вне акватории судового хода в зоне подпора Нижнекамского водохранилища. Целью исследований является предварительная оценка возможности и условий разработки планируемого месторождения ПГП с учетом анализа русловых процессов и безопасных условий судоходства на исследуемом участке реки Белая.

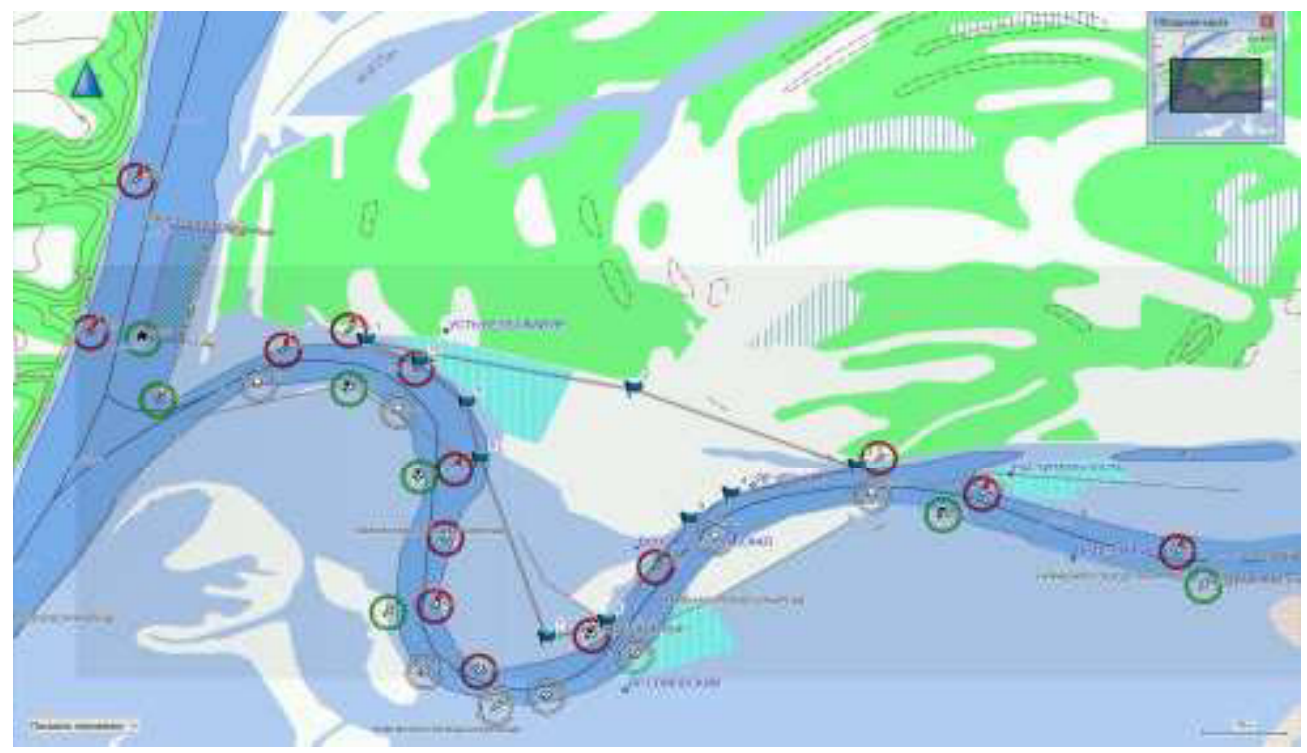

Рис.1. Обзорная схема участка недр на 1757-1763 км р. Белая.

\section{Анализ русловых процессов на исследуемом участке реки Белая.}

Для реки Белая характерен меандрирующий тип руслового процесса. Река на протяжении десятков километров от устья является сильно извилистой, с большим количеством излучин. Рассматриваемый устьевой участок располагается в месте впадения р. Белая в р. Кама, которая, в свою очередь, находится в подпоре Нижнекамского водохранилища. Однако, несмотря на данное обстоятельство, процессы меандрирования на участке выражены в значительной степени, и процесс развития двух последних излучин на р. Белая не завершен и в настоящее время. Для оценки поведения реки и возможности разработки карьера на пойменном устьевом участке в пределах излучины необходимо провести анализ русловых процессов на исследуемом объекте за последние десятилетия.

Излучины, формирующиеся в меандрирующих реках имеют весьма различные углы разворота. На реке Белая наблюдается процесс свободного меандрирования с признаками развития незавершенного. В отличие от излучины ограниченного меандрирования, сползающей вниз по течению без закономерного изменения ее плановых очертаний, на излучине свободного меандрирования меняется угол разворота в сторону увеличения. Изучение переформирований русла за предыдущие годы позволяет достаточно точно указать направление и интенсивность переформирований участка в будущем, что необходимо для проектирования варианта возможного изменения направления судового хода. 
Научные проблемы водного транспорта, выпуск 65, 2020 г.

Для более детальной оценки процесса развития двух нижних излучин необходимо определение следующих измерителей (рис.2):

шаг излучины $\lambda$ - расстояние по прямой между точками перегиба осевой линии, ограничивающими излучину, м;

длина излучины $\mathrm{S}$ - расстояние между теми же точками, измеренное по осевой линии, м;

угол входа $\alpha_{\text {вх }}$ - угол, образованный линией шага и вектором, направленным в сторону течения по касательной к осевой линии в верховой точке перегиба, град.;

угол выхода $\alpha_{\text {вых }}$ - угол, образованный продолжением линии шага и вектором, аналогичным названному выше, но проходящему через низовую точку перегиба, град.;

угол разворота $\alpha$ - угол, образованный двумя названными выше векторами и равный сумме углов входа и выхода, т. е. $\alpha=\alpha_{\text {вх }}+\alpha_{\text {вых }}$;

высота излучины $\mathrm{y}_{\mathrm{T}}$-расстояние от линии шага до наиболее удаленной точки осевой линии, м;

показатель развитости излучины $\mathrm{S} / \lambda$.

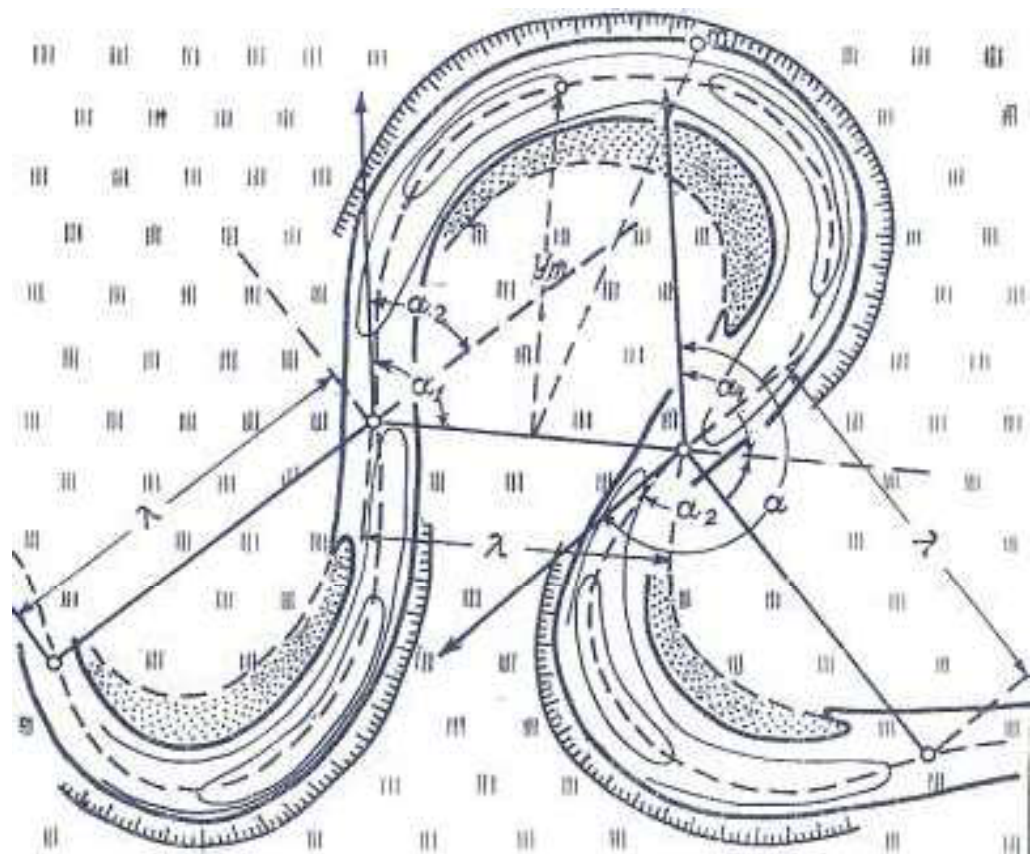

Рис. 2 Измерители меандрирования

Скорость плановых деформаций излучины оценивается следующими измерителями:

- скорость развития угла разворота излучины $\mathrm{C}_{\alpha}$ - отношение изменения угла разворота $\Delta \alpha$ к соответствующему интервалу времени $\Delta \mathrm{t}$, т. е. $\mathrm{C}_{\alpha}=\Delta \alpha / \Delta \mathrm{t}$, где $\Delta \alpha=\alpha_{\mathrm{t}+1}-\alpha_{\mathrm{t}}$;

- скорость развития длины излучины $\mathrm{C}_{\mathrm{S}}$ - отношение изменения длины излучины $\Delta \mathrm{S}$ к соответствующему интервалу времени $\Delta \mathrm{t}$, т. е. $\mathrm{C}_{\mathrm{a}}=\Delta \mathrm{S} / \Delta \mathrm{t}, \Delta \mathrm{S}=\mathrm{S}_{\mathrm{t}+1}-\mathrm{S}_{\mathrm{t}}$;

- скорость перемещения линии берега $\mathrm{C}_{6}, \mathrm{м} /$ год.

Кинематические измерители получены путем сопоставления разновременных съемок или съемок прежних лет с современным положением русла реки. Результаты измерений приведена в таблице 1 . 
А.Н. Ситнов, М.В. Шестова, Ю.Е. Воронина

Прогноз русловых деформаций и особенности разработки пойменных карьеров нерудных ...

Таблица 1

Основные измерения излучины р.Белая в районе предполагаемого месторождения ПГП

\begin{tabular}{|c|c|c|c|}
\hline \multirow{2}{*}{ Параметры } & \multicolumn{3}{|c|}{ Год } \\
\cline { 2 - 4 } & 1994 & 2009 & 2017 \\
\hline$\alpha_{\text {вх1 }}$, & 69 & 83 & 82 \\
\hline$\alpha_{\text {вых } 2}$, & 78 & 75 & 79 \\
\hline$\alpha$, & 147 & 158 & 161 \\
\hline$\lambda_{1}, \mathrm{M}$ & 2120 & 2190 & 2260 \\
\hline$\lambda_{2}, \mathrm{M}$ & 1630 & 1830 & 1910 \\
\hline $\mathrm{y}_{\mathrm{T} 1}, \mathrm{M}$ & 1210 & 1340 & 1350 \\
\hline $\mathrm{y}_{\mathrm{T} 2}, \mathrm{M}$ & 1120 & 1300 & 1440 \\
\hline $\mathrm{S}_{1}, \mathrm{M}$ & 2500 & 2500 & 2500 \\
\hline $\mathrm{S}_{2}, \mathrm{M}$ & 2650 & 3050 & 3200 \\
\hline $\mathrm{S}_{1} / \lambda_{1}$ & 1,18 & 1,14 & 1,11 \\
\hline $\mathrm{S}_{2} / \lambda_{2}$ & 1,62 & 1,67 & 1,68 \\
\hline $\mathrm{C}_{\alpha}$, град/год & - & 0,73 & 0,61 \\
\hline $\mathrm{C}_{\mathrm{S}}, \mathrm{M} /$ год & - & 27 & 24 \\
\hline $\mathrm{C}_{6,} \mathrm{м} /$ год & - & $14-22$ & $6-12$ \\
\hline
\end{tabular}

Примечание: В таблице 1 обозначены: индексом 1 - излучина в районе предполагаемого месторождения ПГП; индексом 2 - ниже расположенная по течению излучина.

При анализе многолетних деформаций рассматривается не русло вообще, а отдельные русловые образования. На участках меандрирующих рек такими образованиями являются отдельные извилины с перекатами и плесовыми лощинами. Эта задача решается путем сопоставления и совмещения планов различных лет съемок. Анализ таких планов позволил выделить следующие характерные этапы и особенности русловых переформирований участка реки.

До 2009 г. интенсивность русловых деформаций на участке была сравнительно велика и заключалась, в основном, в постепенном наращивании длин обеих нижних излучин реки путем размыва береговой полосы верховой и низовой точек перегиба излучин со средней интенсивностью около 14-22 м/год. Такая интенсивность, не характерная для свободных меандрирующих рек (интенсивность размыва свободных меандрирующих рек 30-100 м/год), объясняется подпором Нижнекамского водохранилища, который сглаживает основные плановые деформации путем уменьшения скоростей течения и колебания уровней воды в течение года. Это позволяет затормозить естественный процесс формирования излучин.

Динамика изменений параметров русла на участке определяет усложнение его развития по варианту ограниченного меандрирования.

Ухудшение условий движения потока на рассматриваемом участке вызвано постепенным изменением углов входа и выхода из излучин в сторону увеличения общего угла разворота на $11^{\circ}$. При этом показатель развитости нижней по течению излучины растет с 1,62 до 1,67. Такие показатели характерны для относительно крутых излучин, готовых в естественных условиях развивать зоны будущих проранов. Однако из-за воздействия на реку подпора от Нижнекамского водохранилища показатель развитости излучины не достигает необходимой величины (более 2) и процесс начинает притормаживаться. Таким образом, излучина в том виде, в котором существует на данный момент времени, будет только усугублять условия судоходства в будущем.

В период с 2009 до 2017 гг. (рис. 3) интенсивность русловых деформаций уменьшается (рост излучин сокращается до 6-12 м/год), что говорит об угасании процесса роста искривления русла на устьевом участке. 


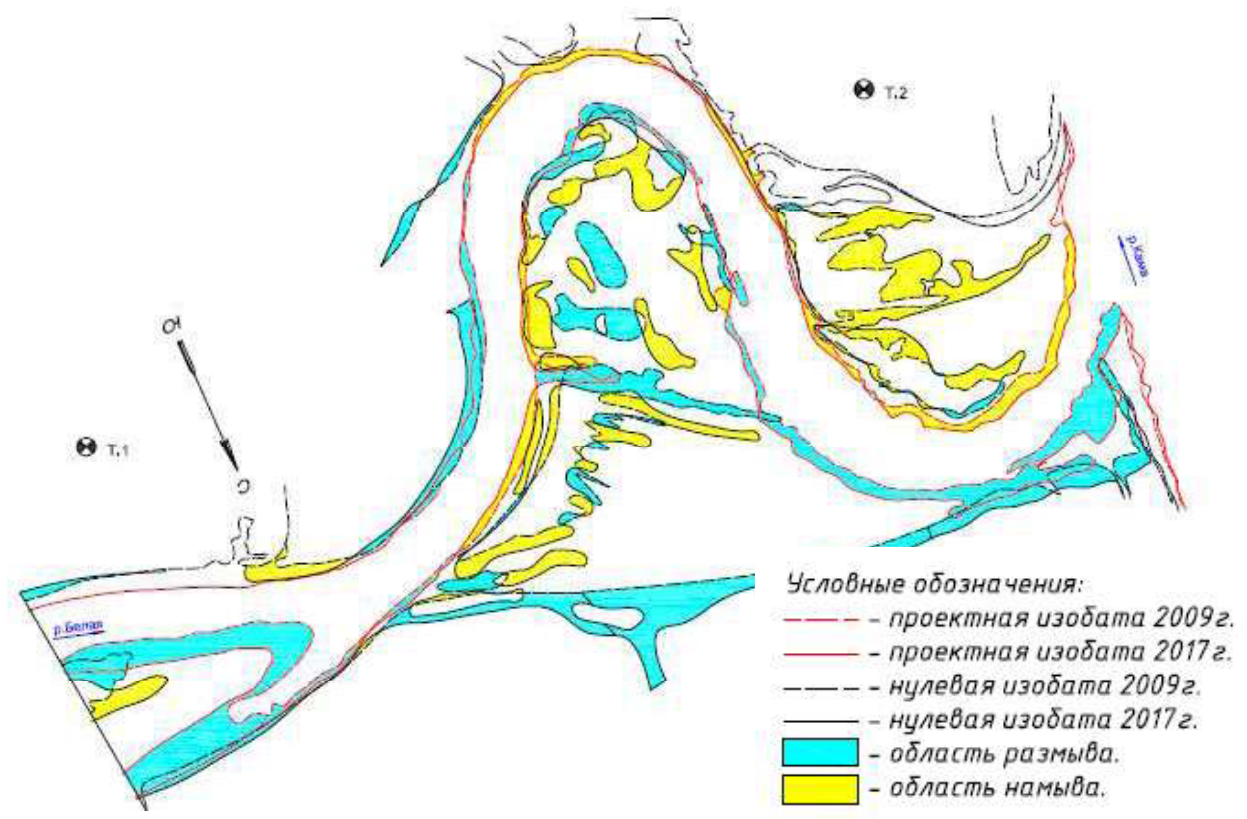

Рис.3. Совмещенные планы 2009 и 2017 г устьевого участка р. Белая

Тенденции к развитию спрямляющей протоки на участке до 2009 года не наблюдалось. Однако уже к 2017 году возникают локальные зоны расширения глубинной эрозии у нижней точки второй по течению излучины и размыва оградительной дамбы между р. Белая и р. Кама.

Пойма внутри первой (верхней из двух) излучины характеризуется разнонаправленными деформациями, возникающими также за счет подпора Нижнекамского водохранилища. Рассматриваемый участок р. Белая находится в зоне выклинивания подпора указанного водохранилища, которая характеризуется наличием временного подпора - в межень при наполненном водохранилище. В зимний период при частично опорожненном водохранилище и во время половодья на реке в зоне выклинивания подпор отсутствует. В это время гидрологический и русловой режимы зоны аналогичны режимам свободной реки. Во время подпора режим зоны выклинивания приближается к режиму речной части водохранилища. Кроме того, необходимо учитывать, что по данным Берковича К.М. [1], начиная с 1965 г., из русла р.Белой и прирусловой поймы было извлечено более 85 млн. м ${ }^{3}$ песчано-гравийного аллювия, что оказало определенное влияние на морфологическое строение реки, на ее водный и русловой режим.

\section{2. Обоснование рекомендуемых параметров и условий добычи ПГП с учетом безопасных условий судоходства}

В меандрирующих руслах рек обеспечивать устойчивость излучин при карьерных разработках достаточно сложно. Ввиду большой подвижности таких русел выбор места расположения карьера обычно затруднен. Существуют следующие рекомендации при размещении карьеров НСМ на пойме [2,3,4]:

1. Допускается проектирование карьеров НСМ (с ограждением участков добычи НCM защитными дамбами) на пойменных участках и и во второстепенных рукавах русел с незавершенным меандрированием и пойменной многорукавностью. 
2. Оптимальным местом размещения карьера на излучине представляется низовая часть пляжа. Добыча материала допустима и на других участках пляжа (поймы), не нарушающих общей морфологии русла, например, в виде поперечных прорезей.

3. Не рекомендуется размещать карьеры на верховом и низовом перекатах излучин, т. к. их размещение на указанных макроформах приводит к значительному перехвату карьером влекомых наносов, что в свою очередь, оказывает влияние на развитие смежных излучин.

Планируемый карьер ПГП занимает практически всю правобережную пойму, захватывая в том числе ее основание (рис.4). При разработке всего карьерного поля на участке произойдут необратимые русловые деформации, которые существенно осложнят судоходную обстановку. Для минимизации подобных рисков следует предусмотреть чёткую поэтапность отработки карьера и проектирование зоны, не подлежащей отработке (охранного целика). При разработке карьера значительной площади изменение расходов воды и скоростей течения по ширине русла могут привести к перемещению динамической оси потока на акваторию карьера и образованию вторичных течений. Такого рода карьеры следует проектировать совместно с путейскими организациями в комплексе с коренным улучшением судоходных условий.

Кроме того, на исследуемом участке реки Белая существуют сложности в организации судоходства, которые связаны, в том числе, с ограниченной просматриваемостью судов. На 1760,8-1759,1 км расхождение и обгон составов и крупногабаритных судов длиной более 120 м не рекомендуется. Для пропуска встречных судов и составов идущие вверх суда должны останавливаться на 1759 км справа от оси судового хода. В целом участок 1759-1753 км является зоной повышенной опасности и при движении здесь необходимо соблюдать особую осторожность.

Развитие излучин при незавершенном меандрировании может быть легко приостановлено в результате внешних воздействий. Например, путем создания новых спрямлений. С учетом этого в границах карьера можно выделить первоочередной участок по добыче НСМ, который одновременно будет являться акваторией нового судового хода.

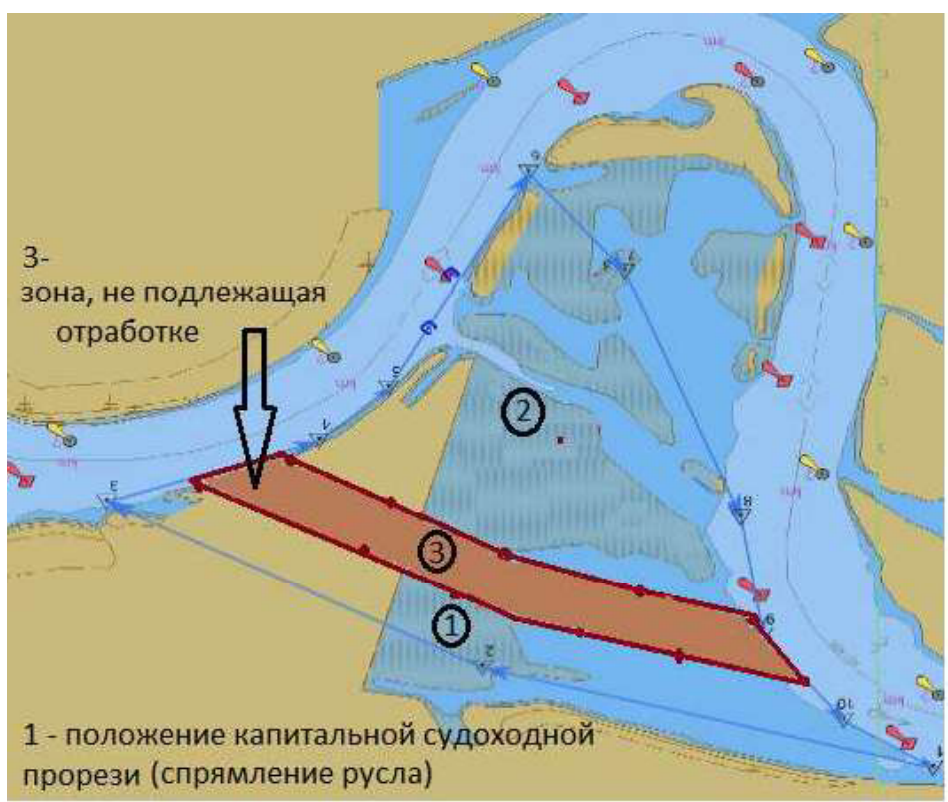

Рис.4. Схема разбивки на участки очередности отработки карьера: 1-положение капитальной судоходной прорези (спрямление русла), 2 - пойменная часть карьера, подлежащая отработке; 3 - зона, не подлежащая отработке (охранный целик). 
Научные проблемы водного транспорта, выпуск 65, 2020 г.

Раздел V. Водные пути, порты и гидротехнические сооружения

Параметры нового создаваемого русла должны быть сопоставимы с параметрами современного русла на его судоходном участке, а именно: ширина должна быть выдержана не менее 200 м с тем, чтобы обеспечить двухстороннее движение судов; а глубина не менее максимальной фактической глубины в современном русле 14 м. В этом случае площадь живого сечения русла составит около $3000 \mathrm{~m}^{2}$ и тем самым будет обеспечен расход воды, проходящий сейчас в основном русле.

Учитывая гидравлику потока, необходимо отметить, что обязательным является наличие перемычки с повышенными отметками, которая отделит будущий основной судовой ход от акватории оставшейся части карьера и, по сути, будет выполнять роль защитной дамбы (блок № 3 на рис.4). Согласно [4], границы карьера должны находиться от оси перемычки (или дамбы) на расстоянии более пятикратной глубины карьера. Таким образом, ширина перемычки (блока №3) должна составлять не менее 150 м, и ее разработка недопустима. Для ее формирования и укрепления рекомендуется вскрышные породы укладывать на нее.

Разработку прорези (блока №1) следует начинать снизу вверх от 1757 км. Окончательное спрямление русла (прорыв меандра) следует выполнить в конце навигации. Постольку по длине блок №1 имеет большую протяженность (около 3,0 км), то его отработка будет производиться в течение нескольких лет. При этом следует отметить, что при организации работ по добыче ПГП в районе 1757 км от кромки судового хода до внешней границы блока должна сохраняться 30-метровая свободная зона для закладки становых якорей земснаряда и установки барж под погрузку. Поэтому для соблюдения этих возможно требований потребуется ограничение длины отрабатываемого блока на 20-30 м на участке 1757 - 1758 км.

После решения вопросов организации судоходства и выставления нового навигационного ограждения можно перейти к разработке пойменной части карьера (блок №2). При этом старое русло рекомендуется перекрыть в истоке и, таким образом, сосредоточить сток воды и наносов в спрямлении. Разработку блока №2 рекомендуется начать с его верхней части с тем, чтобы в районе нового судового хода стабилизировался процесс русловых деформаций. У границы блока, примыкающей к перемычке, необходимо планировать добычные работы, исходя из условия недопущения разрушения ее берегов при образовании естественных откосов в разработанном карьере менее 1:4.

Самым важных вопросом при организации добычных работ является обеспечение безопасности судоходства на устьевом участке р. Белая. Определяющим требованием является обеспечение безопасного судоходства транзитного флота и маневрирования устанавливаемых под погрузку к добычной технике судов и составов, а также при их отводе на рейд формирования после погрузки. Необходимо также отметить, что концентрация судов в одном месте, в первую очередь, на криволинейных участках судового хода, снижает безопасность судоходства в связи с дезориентацией судоводителей, особенно в ночное время при большом скоплении огней.

В соответствии с правилами организации рейдов [4] не допускается их размещение в местах поворотов судового хода. Кроме того, Правилами плавания [5, Ст.199] запрещена стоянка судов в крутых коленах и на подходах к ним, у берегов с прижимным течением, на входах в притоки и выхода из них. С учетом этого рейды при организации добычных работ на блоке №1 должны быть организованы за пределами судового хода 1757-1763 км. Возможна их организация ниже по течению на р. Кама.

Рейды целесообразно организовать в районе селения Усть-Бельское вдоль правого берега (1753 км) на р. Кама, как на месте бывшего рейда нефтеналивных судов, так и ниже по течению. Русло реки на данном участке широкое, прямолинейное, глубины большие. Правый берег высокий, коренной, который прикрывает рейд от действия северных ветров.

В целом добычные работы целесообразно вести в светлое время суток с тем, чтобы не увеличивать нагрузку на судоводителей и не дезориентировать их в темное 
время. При организации работ в темное время суток в качестве альтернативы может быть рассмотрен вариант с корректировкой светового оборудования на кромочных навигационных знаках (с заменой белых огней на зеленый) либо на всем протяжении рассматриваемого участка, либо ограничиться 1757-1758 км.

Также может быть рекомендовано отработку первой серии на блоке №1 в районе 1757-1758 км вести только в светлое время суток, однако данный вопрос должен быть проработан на следующем этапе проектирования при разработке организации добычи НСМ. Следует отметить, что работа на первой серии блока №1 в темное время суток возможна при надежной гарантии отсутствия движения транзитных судов в это время на рассматриваемом участке, что должно быть оговорено специальными условиями.

Создание спрямляющего судового хода устранит имеющиеся сложности в прохождении судами участка 1763-1757 км, что целесообразно осуществить до возможного наполнения до проектной отметки Нижнекамского водохранилища, которое может быть реализовано в перспективе. Однако, при повышении уровня НПУ в Нижнекамском водохранилище с 63,3 мБС на проектный уровень 64,0 мБС (на 70 см) коренным образом ситуацию с трудностями судоходства, имеющимися в настоящее время на излучине, не улучшит. Только спрямление судового хода может обеспечить безопасное плавание судов на устьевом участке р. Белая. Для обеспечения безопасности судоходства при входе и выходе из предполагаемого спрямления необходимо предусмотреть расстановку навигационного оборудования в соответствии с требованиями ГОСТ 26600-98 [6].

В этой связи разработанный улучшенный судовой ход послужит основой проектных решений транспортного освоения участка при подъеме Нижнекамского водохранилища и исключит трудности разработки будущей спрямляющей трассы для района водных путей и судоходства Администрации бассейна в новых гидрологических условиях, связанных с повышением уровня воды и ухудшением ориентации в зоне трассы, что также осложнит судоходные условия.

\section{Вывод}

Таким образом, добыча НСМ на исследуемом участке реки Белая в принципе возможна только при условии комплексного решения вопросов, связанных с безопасностью судоходства. В первую очередь, это спрямление меандра и перенос судового хода в новую капитальную прорезь. За счет этого будут устранены те сложности, которые сейчас существуют в организации судоходства, а также будет уменьшена протяженность пути на этом участке на 3 км.

\section{Список литературы:}

1. Беркович К.М. Русловые процессы и русловые карьеры. - М.: 2005. - с.109.

2. СТО 52.08.31-2012. Добыча НСМ в водных объектах. Учет руслового процесса и рекомендации по проектированию и эксплуатации русловых карьеров /Министерство природных ресурсов и экологии РФ/. Сп-б. 2010 г.

3. Рекомендациям по прогнозу деформаций речных русел на участках размещения карьеров и в нижних бьефах гидроузлов, - Ленинград: Транспорт, 1988 г.

4. Руководство по проектированию русловых карьеров. Мероприятия по предотвращению понижения уровней воды / Министерство речного флота РСФСР/, Ленинград: Транспорт, 1987 г. 5. Правила плавания по внутренним водным путям. / Утв. приказом Минтранса России от 19 января 2018 г. № 19.

6. ГОСТ 26600-98. Знаки навигационные внутренних судоходных путей. ИПК. - Изд-во стандартов, $2001-32 \mathrm{c}$.

7. Гришанин К.В. и др. Водные пути. - М.: Транспорт, 1986 г.

8. Рекомендации по учету естественных циклических деформаций русел равнинных рек при строительном проектировании / Министерство энергетики и электрификации СССР/ Ленинград: Гидрометеорологическое издательство, 1969 г.

9. Knighton D. Fiuvial forms and processes. London, Arnold.1984.218p. 
Научные проблемы водного транспорта, выпуск 65, 2020 г.

Раздел V. Водные пути, порты и гидротехнические сооружения

10. Knighton D. Fiuvial forms and processes. A new perspective. London, Arnold.1998. 383p.

11. Bagnold R.A. An approach to the sediment transport problem from general physics. - US. Geol. Survey, 1966, Prof. Paper

12. Graf W.H., Acaroglu E.R. Sediment transport in conveyance systems (Part I) - Bull. Int. Assoc.

Sci. Hydr., XIII annee №2.1968

13. Lagasse P.F.. Winkley B.R., Simons D.B. Impact of gravel mining on river system stability// Journal of the Waterway, Port, Coastal, and Ocean Division. Vol. 103. 1980. №3. P. 389-404.

14. Galay V.J. Causes of River Bed Degradation// Water resources research, 1983, vol.19, №5. P.1057-1090.

15. Graf W.L. The rate law in fluvial geomorphology. - American Journal of Science. 1977, 277. P.178-191.

16. Gregory K. Walling D. Human activity and environmental processes. London. 1987. 235.

\title{
CHANNEL DEFORMATIONS FORECAST AND FEATURES OF FLOODPLAIN QUARRIES OF NON-METALLIC CONSTRUCTION MATERIALS DEVELOPMENT IN MEANDERING RIVERBEDS BASED ON SAFE NAVIGATION CONDITIONS (ON THE EXAMPLE OF THE BELAYA RIVER)
}

\author{
Aleksandr N. Sitnov \\ Volga State University of Water Transport, Nizhny Novgorod, Russia \\ Yulia E. Voronina \\ Volga State University of Water Transport, Nizhny Novgorod, Russia \\ Marina V. Shestova \\ Volga State University of Water Transport, Nizhny Novgorod, Russia
}

\begin{abstract}
Floodplain quarries of non-metallic construction materials (NCM) have a minimal impact on the water regime and navigable conditions of the reservoir in the area of their location. However, the development of such deposits has its own characteristics, especially in case of their location in meandering beds of large navigable rivers. On the example of floodplain quarry located at the mouth of the Belaya river $(1757-1763 \mathrm{~km})$, development conditions for such facilities based on ensuring navigation safety were considered; on the basis of changes' dynamics in the bends' main parameters the channel state assessment and fluvial deformations forecast were made. It was concluded that it is possible to extract sand and gravel in the studied section of the Belaya river, provided that navigation safety issues are resolved in a comprehensive manner. First of all, it refers to meander straightening and transferring the ship's course to a new capital slot.
\end{abstract}

Keywords: floodplain quarries of NCM, channel deformations forecast, meandering riverbeds, navigable conditions

\section{References:}

1. Berkovich K.M. Ruslovye processy i ruslovye kar'ery. - M.: 2005. - s.109.

2.STO 52.08.31-2012. Doby cha NSM v vodny`x ob "ektax. Uchet ruslovogo processa i rekomendacii po proektirovaniyu i e'kspluatacii ruslovy'x kar'erov/Ministerstvo prirodny'x resursov i e'kologii RF/. Sp-b. 2010 g.

3.Rekomendaciyam po prognozu deformacij rechny`x rusel na uchastkax razmeshheniya kar'erov i v nizhnix b`efax gidrouzlov, - Leningrad: Transport, $1988 \mathrm{~g}$.

4.Rukovodstvo po proektirovaniyu ruslovy'x kar'erov. Meropriyatiya po predotvrashheniyu ponizheniya urovnej vody` / Ministerstvo rechnogo flota RSFSR/, Leningrad: Transport, $1987 \mathrm{~g}$.

5.Pravila plavaniya po vnutrennim vodny`m putyam. / Utv. prikazom Mintransa Rossii ot 19 yanvarya 2018 g. № 19. 